\title{
Tuning electricity generation throughout the year with PV module technology
}

Patrizio Manganielloa,b,1, Jonathan Govaerts ${ }^{a, b^{*}}$, Imre T. Horvath ${ }^{a, b}$, Gofran Chowdhurya,b,c, Georgi H. Yordanov ${ }^{\mathrm{b}, \mathrm{c}}$, Hans Goverde ${ }^{\mathrm{a}, \mathrm{b}, 2}$, Bader Aldalalid, Ian Beausoleil-Morrison $^{\mathrm{e}}$, Seppo Valkealahti ${ }^{f}$, Kari Lappalainen ${ }^{\mathrm{f}}$, Jef Poortmans, ${ }^{\mathrm{a}, \mathrm{b}, \mathrm{c}, \mathrm{g}}$

aimec, Kapeldreef 75, Leuven, Belgium;

bEnergyVille, ThorPark 8310, Genk, Belgium; cUniversity of Leuven, Dept. of Electrical Engineering (ESAT), Leuven, Belgium; dKuwait University, College of Engineering and Petroleum, Khaldiya, Kuwait;

e3Carleton University, Ottawa, Canada;

'Tampere University of Technology, Electrical Energy Engineering, Tampere, Finland; gUniversity of Hasselt, Martelarenlaan 42, Hasselt, Belgium.

"Corresponding author, email: Jonathan.Govaerts@imec.be; ${ }^{1}$ now with TUDelft; ${ }^{2}$ now with Jan De Nul

\section{Abstract}

Currently, photovoltaic (PV) installations target a maximization of annual energy yield. In the future however, electricity generation may need to match better with the load profiles in a given environment and climate. In particular this will be a challenge for generation across the seasons, where electrical storage is less suitable, and in the built environment, where wind turbines for generation are much more difficult to integrate.

In this paper we discuss how this challenge may be addressed with climate- and consumption-specific PV module technology. In particular, we demonstrate how the temperature coefficient of a PV system can impact the energy yield throughout the year. After explaining the concept, we apply our electrical-optical-thermal model to do very accurate physics-based bottom-up simulations in different climates. As such, depending on the climate and latitude, a higher temperature coefficient of the PV module may lead to higher energy yields, mostly during the colder season. We also demonstrate that, if higher temperature coefficients are accompanied by improved low-light performance (tunable using the module's series resistance), the seasonal gain can be much higher. We indicate the relevance of our assumptions by basing the module performance in the simulations on (datasheets of) commercial modules.

\section{Keywords}

PV module technology, energy yield simulation, temperature coefficient, low-light performance, seasonal balancing by tuning PV generation

\section{Background}

Currently, the main target in photovoltaic (PV) installations is on getting as much energy as possible out of a module, resulting in a maximization of annual energy yield, 
namely the energy produced $(\mathrm{kWh})$ per installed nominal power $(\mathrm{kWp})$, in order to achieve the highest possible return on investment. This is a good target in case of:

- Low PV penetration rates such that PV electricity can be easily absorbed by the grid

- A generation profile reasonably aligned to the consumption profile (e.g. cooling needs in hot climates)

- Expensive modules/systems

- A fixed electricity pricing throughout the year

In general, it is a good target if the grid overhead (distribution cost) is limited and the generated energy can be immediately (and locally) consumed, or if storage is readily available (and cheap). However, this is not necessarily the case if the grid overhead 50 dominates over module cost, so in the opposite situation of high PV penetration rate, mismatch between generation and consumption, cheap modules/systems and low or even negative electricity pricing in PV production highs. In such an environment, it may be beneficial to look at better balancing generation and load profiles. This can be done through demand-side-management and integration of storage in the system, but also from the generation side, by tuning the production peaks towards the times of need. It can be relevant on a seasonal level, as well as intraday, and one of the easiest ways of doing this is by optimizing orientation and tilt angles of PV generators, but also the temperature-dependent performance of the used modules can provide a knob for such tuning.

In particular for colder climates, it can be of interest to reduce overall yearly energy yield in favor of a better match in the cold season. Figure 1 conceptually, in an extreme situation, illustrates how a PV system (PV system 2 in Figure 1) may better match the consumption level (in this case fixed throughout the year) than a system maximizing overall yearly energy yield (PV system 1 in Figure 1).

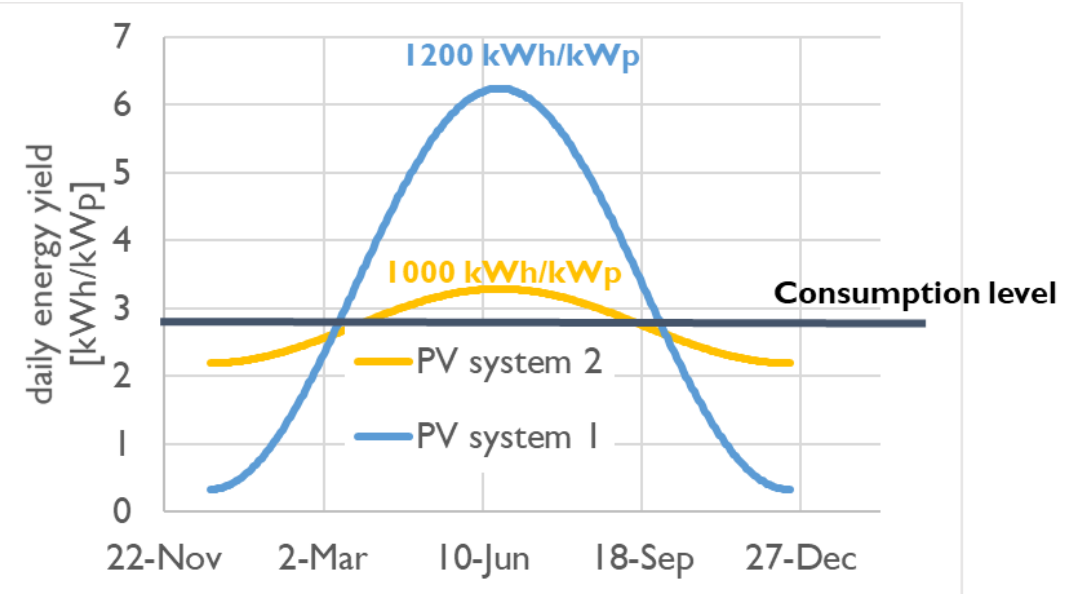

Figure 1: Conceptual illustration indicating how a PV system may sacrifice its overall yearly energy yield for a better match to the seasonal consumption level 
While PV systems are typically already matching consumption by default in warmer climates, where production is well aligned with the demand for electrical cooling [1], in colder climates yearly energy yield is sometimes sacrificed for matching daily morning and evening peaks (east-west orientation) or seasonal variations (tilt). Especially the latter one is of interest, since the former one can be solved relatively straightforward through electrical storage, while on a seasonal level this would be much more challenging and costly. Figure 2 illustrates how tilting a South-oriented panel allows to influence its yearly insolation, and therefore energy generation, profile. This simulation illustrates how difficult (or impossible) it is in the Paris climate to optimize for winter production with varying tilt alone, while it is very easy in Kuwait, given the constant amount of sunlight.
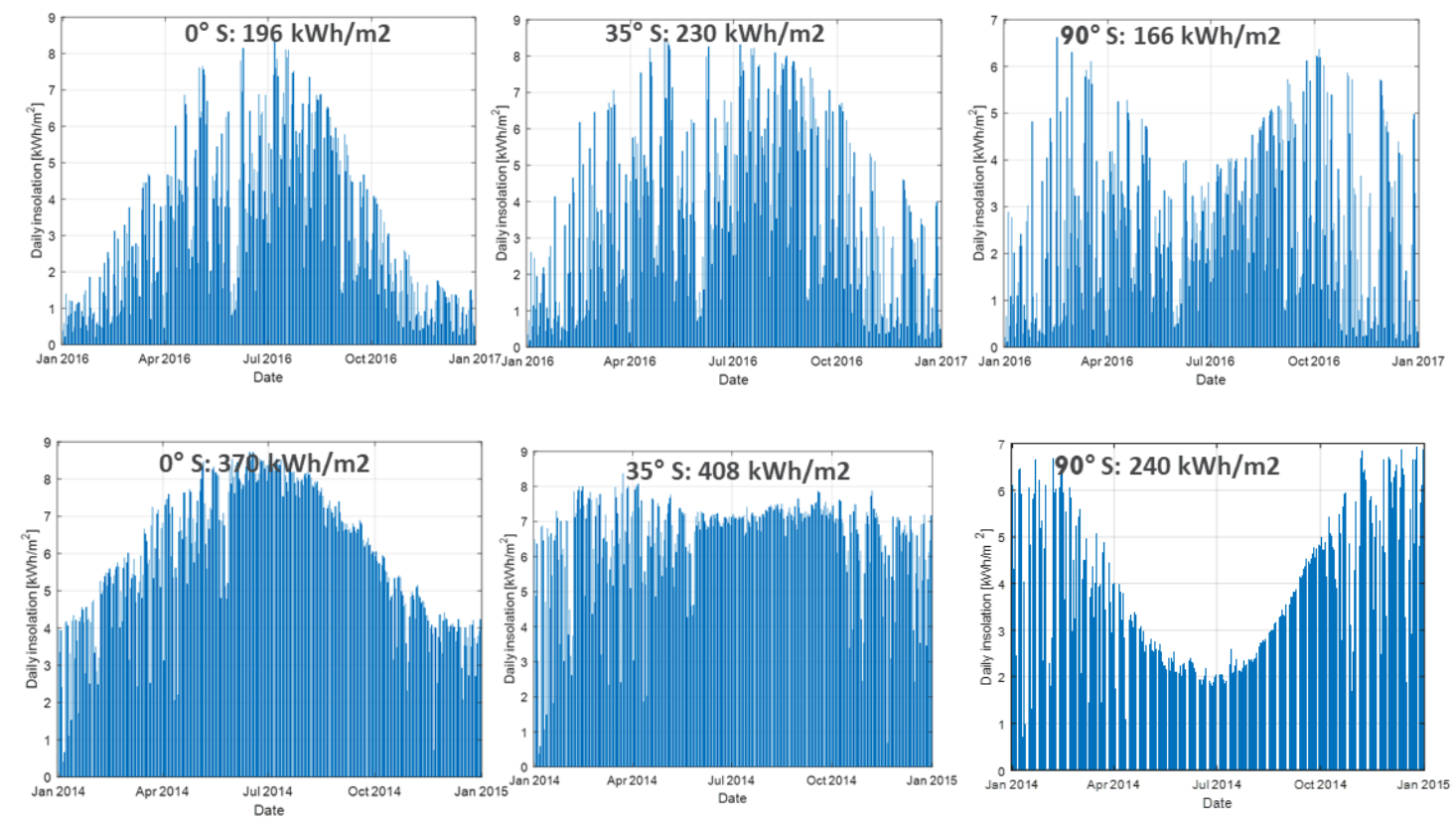

Figure 2: Impact of tilt angle $\left(0^{\circ}, 35^{\circ}\right.$ and $\left.90^{\circ}\right)$ on received daily insolation (across a full year) and overall yearly energy production of a south-oriented panel for Paris (top) and Kuwait (bottom)

On the other hand, the PV module technology itself is sometimes adapted to cope with the installation climate and environment, though implementation is usually focused on limiting degradation (e.g. extra moisture intrusion protection in hot-humid conditions or radiation protection in high UV conditions or space) and overall performance losses (e.g. increased metal cross-sections for cell interconnection for systems with higher peak irradiance of the modules due to climatic conditions or bifaciality).

The above approaches mainly focus on the first-order effects induced by variations in irradiation. In this paper, we want to indicate another possibility to take into account the expected climate and consumption patterns for a system, in particular the secondorder effects of temperature on the performance, by tuning the temperature coefficient 
97 conceptually and greatly simplified, how the cell temperature will result in a flattening 98 of the energy yield output over the year, and increasingly so for modules with a higher 99 temperature coefficient. Depending on the exact conditions, the energy yield could 100 even be potentially higher in the cold season for modules with a higher temperature I0I coefficient.

102

103

104

105

106

107

108

109

110

III

112

113

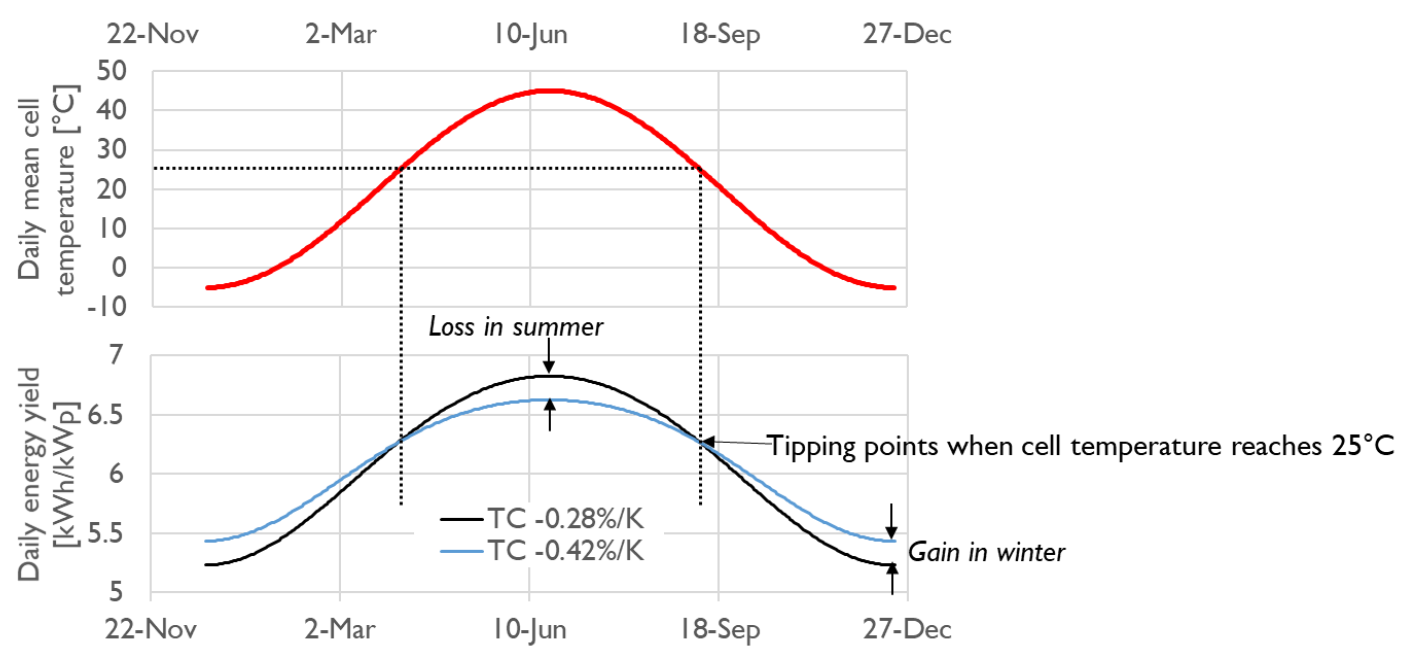

Figure 3: Conceptual indication of the impact of differences in temperature coefficient for maximum power (TC) on seasonal energy yield fluctuations 


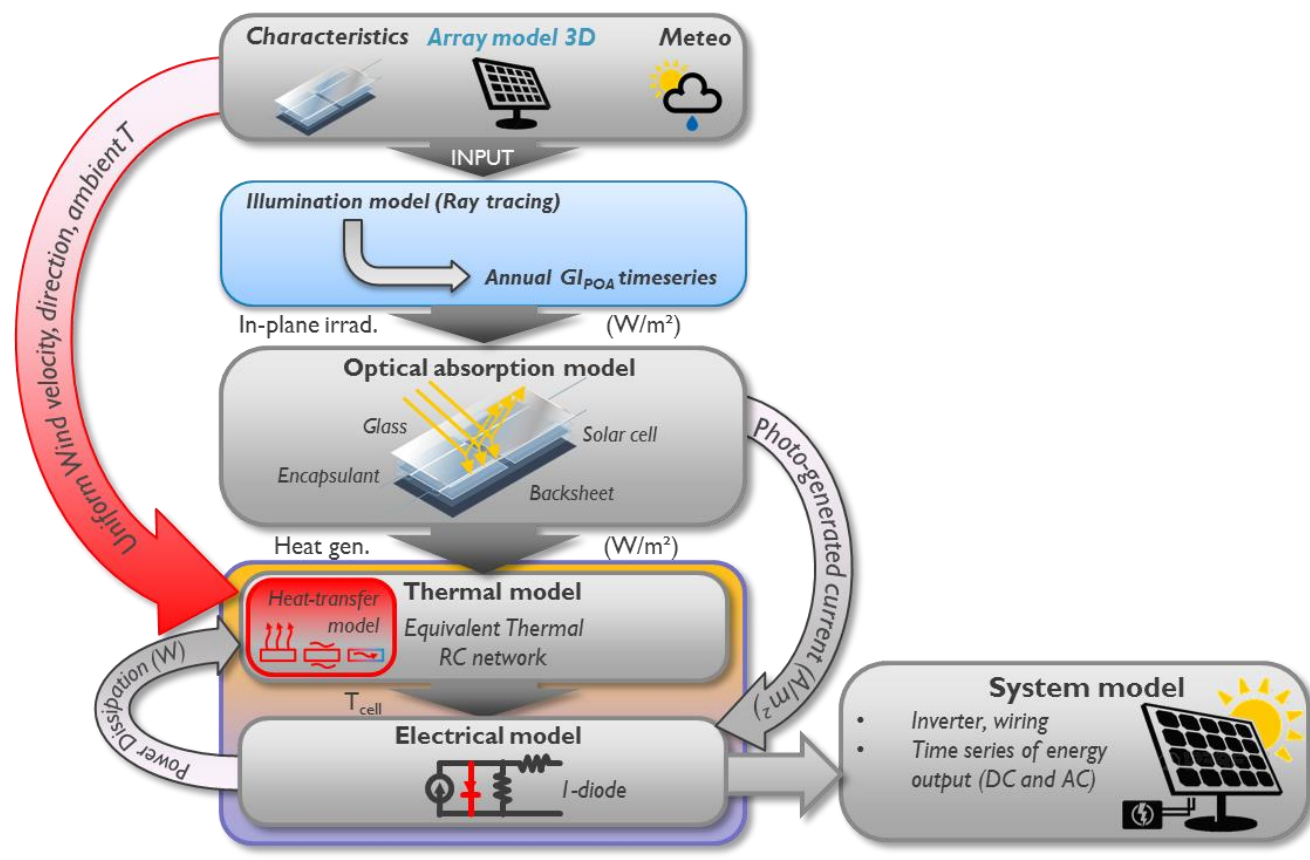

Figure 4: Conceptual representation of the used modeling framework [2], [2]

II8 Climate data have been collected across a full year with a resolution of 1 minute from

II9 4 locations: Kuwait City (Kuwait), Oldenburg (Germany), Ottawa (Canada) and

I20 Tampere (Finland). These diverse locations allow to illustrate the impact of the I2I temperature coefficient of the module technology in different climates and latitudes.

I22 Measured wind velocity (speed and direction), ambient temperature, Global Horizontal

123 Irradiance $(\mathrm{GHI})$ and Diffuse Horizontal Irradiance (DHI) were available at every I24 location. Using the Perez model [3], [5], Plane-Of-Array (POA) Irradiance is calculated I25 (from the GHI and DHI values) at every location for the full year. We assume the PV 126 panels are South-oriented, with tilt angle at each latitude optimized for annual energy 127 yield [6], as shown in Table 1, where also their respective Köppen-Geiger classification 128 [7] is displayed.

Table 1. Tilt angles [6] and climate classifications [7] for the PV installations simulated in the study

\begin{tabular}{|l|c|c|}
\hline \multicolumn{1}{|c|}{ Location } & Tilt angle [ ${ }^{\circ}$ ] & $\begin{array}{c}\text { Köppen-Geiger } \\
\text { climate } \\
\text { classification }\end{array}$ \\
\hline Kuwait City (Kuwait) & 26 & BWh \\
\hline Oldenburg (Germany) & 33 & Cfb \\
\hline Ottawa (Canada) & 37 & Dfb \\
\hline Tampere (Finland) & 40 & Dfb \\
\hline
\end{tabular}


I33 Stand-alone commercially available conventional PV modules made of 60 cells in portrait installation have been considered for the energy yield simulations. Hence, module-level maximum power point tracking (MPPT) has been assumed. For the temperature-dependent PV module behaviour, we always refer to the temperature coefficient for maximum power abbreviated as TC.

\section{Energy yield simulations: results and discussion}

The simulations have been carried out to determine absolute and relative differences in energy yield between PV module technology that is currently commercially available. As such, the module parameters needed for these simulations, namely photo-generated current, temperature-independent coefficient of diode saturation current, diode ideality factor, and series and shunt resistances, have been calibrated directly from actual module datasheets. Each time, modules with same rated power and area have been selected to ease comparison.

\subsection{Impact of temperature coefficient}

I49 In this first case, two different types of PV module have been considered, one with a temperature coefficient for maximum power (TC) equal to $-0.42 \% / ㅇ ㅡ$ [8], the other with a temperature coefficient for maximum power equal to $-0.28 \% / ㅇ ㅡ .99]$. In the following, we refer to them as HTC and LTC, respectively. These modules have been chosen as their TC values are representative of the extremes currently available in the high-end market. Based on the datasheet values, summarized in Table 2, the HTC module could be representative for state-of-the-art PERC technology, while the higher

Voc for the LTC module indicates a technology with passivated contacts.

Table 2. PV module parameters from datasheets

\begin{tabular}{|c|c|c|}
\hline Parameter & HTC [8] & LTC [9] \\
\hline Short-circuit current $I_{s c}[\mathrm{~A}]$ & 9.78 & 9.38 \\
\hline Open-circuit voltage $V_{o c}[\mathrm{~V}]$ & 40.26 & 43.89 \\
\hline Maximum power $P_{m p}[\mathrm{~W}]$ & 305 & 305 \\
\hline Current at maximum power $I_{m p}[\mathrm{~W}]$ & 9.31 & 8.66 \\
\hline Voltage at maximum power $V_{m p}[\mathrm{~W}]$ & 32.76 & 35.22 \\
\hline $\begin{array}{c}\text { Temperature coefficient of } P_{m p}(\mathrm{TC}) \\
{[\% / \stackrel{\circ}{ } \text { C] }}\end{array}$ & -0.42 & -0.28 \\
\hline
\end{tabular}


160 For detailed (daily) accurate energy yield simulations is important to also assess the 161 low-light performance of both modules as much as possible from the information 162 available in the respective datasheets. In the case of LTC [9], it is claimed that the PV 163 module shows " $3.5 \%$ relative efficiency reduction at low irradiance $\left(200 \mathrm{~W} / \mathrm{m}^{2}\right)$ ", 164 whereas the datasheet of HTC [8] includes a graphic of normalized peak power as a 165 function of irradiance. This information has been included in the module parameters' 166 fitting procedure, leading to the results shown in Figure 5. From Figure 5(a), it is 167 evident that LTC performs better than HTC at low light. On the other hand, Figure 5(b) 168 shows that $\mathrm{LTC}$ performs worse than $\mathrm{HTC}$ when the temperature is below $25^{\circ} \mathrm{C}$. Thus, 169 the improved efficiency of HTC due to lower temperature in cold climates is 170 counteracted by a decreased efficiency at low irradiation. In the following subsections, 171 we elaborate and discuss the relative outcome of the simulations with the two PV 172 modules in the cases of the four installation sites using their relevant climatic data.

173

174

175

176

177

178

179

180

181

182

183

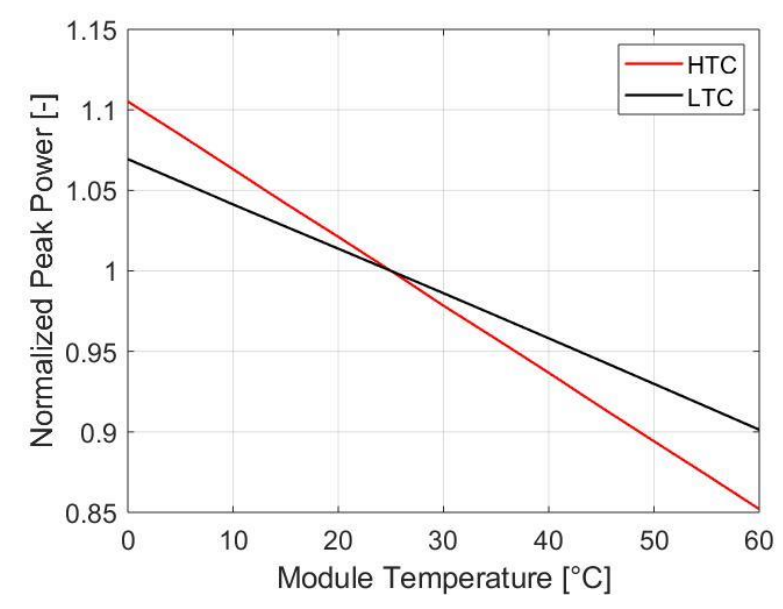

(b)

Figure 5: Performance of the PV modules under analysis. (a) low-light behavior at a fixed cell temperature of $25{ }^{\circ} \mathrm{C}$ and (b) Thermal behavior at a fixed irradiation of $1000 \mathrm{~W} / \mathrm{m}^{2}$.

\subsubsection{Kuwait installation}

Starting with the hottest climate, at a latitude of $29.4^{\circ} \mathrm{N}$, it is immediately clear that here a low temperature coefficient is highly preferable. With an average ambient temperature of $29^{\circ} \mathrm{C}$ and high irradiation levels throughout the year, as shown in Figure 6 , the cell temperatures are obviously continuously over $25^{\circ} \mathrm{C}$ (with an average over operational hours higher than $40^{\circ} \mathrm{C}$ ). 


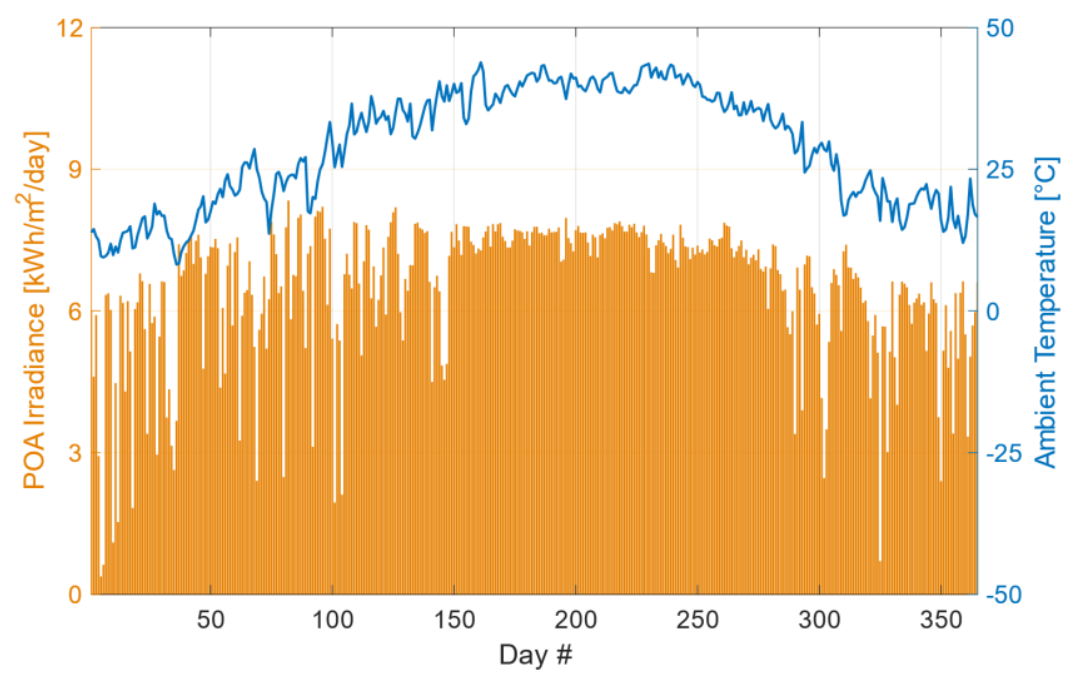

Figure 6: Daily POA irradiance (orange bars) and daily average (over operational hours) ambient temperature (blue curve) values throughout 2014, obtained from the Kuwait data used for the simulations.

Figure 7 shows the simulated daily energy yields as well as the difference between the two PV modules. As the energy yield is referenced to the nominal power (Wp) of the module at $25^{\circ} \mathrm{C}$, the high operational temperature will lead to improved energy yields for PV modules with a lower temperature coefficient. As expected, with the exception of a few days, PV modules with a lower temperature coefficient generate a higher energy yield all over the year in this type of climate.
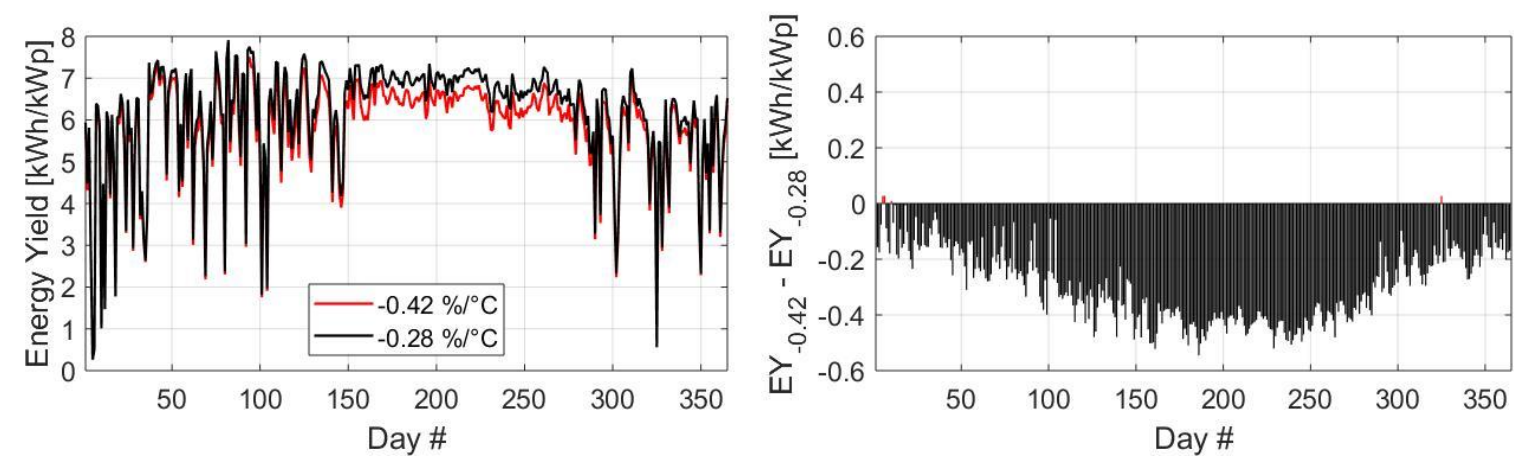

Figure 7: simulated daily energy yield throughout 2014 for the HTC and LTC modules (left), and the resulting difference (right). Red bars in the right plot refer to days where the HTC module leads to a higher energy yield (positive values in the graph, almost none present) than the LTC module. The opposite case is represented by the black negative bars.

While the relative annual energy yield difference amounts to $-4.8 \%$, cf. Table 3 , the difference peaks to $-6.4 \%$ in the summer season, as shown further on in Figure 15. Moreover, hot desert climates as in Kuwait require little heating in winter, but all the more cooling in summer. This translates in an increased electricity consumption in 
summer [1], and so the higher production from the low-temperature-coefficient PV system is even more attractive.

\subsubsection{Oldenburg installation}

210 In a more moderate climate in Western Europe, at a latitude of $53.1^{\circ} \mathrm{N}$, the results are 2II somewhat similar to the Kuwait ones, but with many additional days of gain due to the 212 use of PV modules with a higher thermal coefficient. With the lower overall 213 temperature and higher fluctuations in irradiance, shown in Figure 8, the differences 2I4 in daily energy yield between different PV module temperature coefficients for the 215 simulated year are smaller than in Kuwait. As shown in Figure 9, the use of PV 216 modules with a higher thermal coefficient allows for a slightly higher overall energy 217 yield during the first and last months of the year, thus during fall and winter months.

218 However, the losses during spring and summer are much higher, leading at last to a 219 yearly energy loss around $2.4 \%$ (Table 3 ).

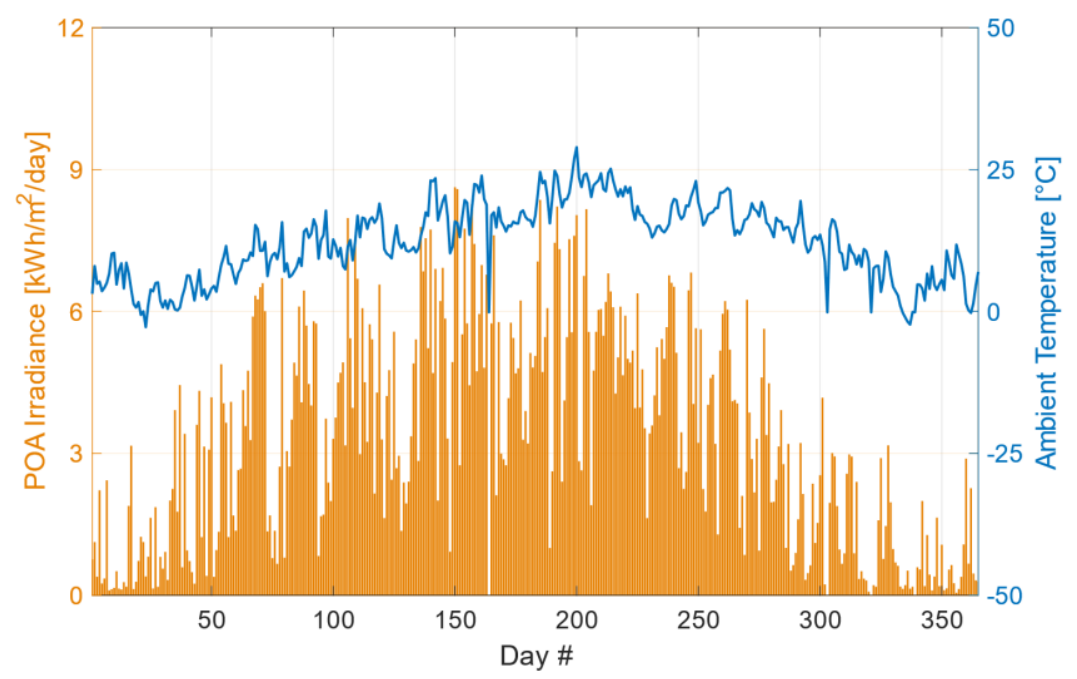

Figure 8: Daily POA irradiance (orange bars) and daily average (over operational hours) ambient temperature (blue curve) values throughout 2014, obtained from the 


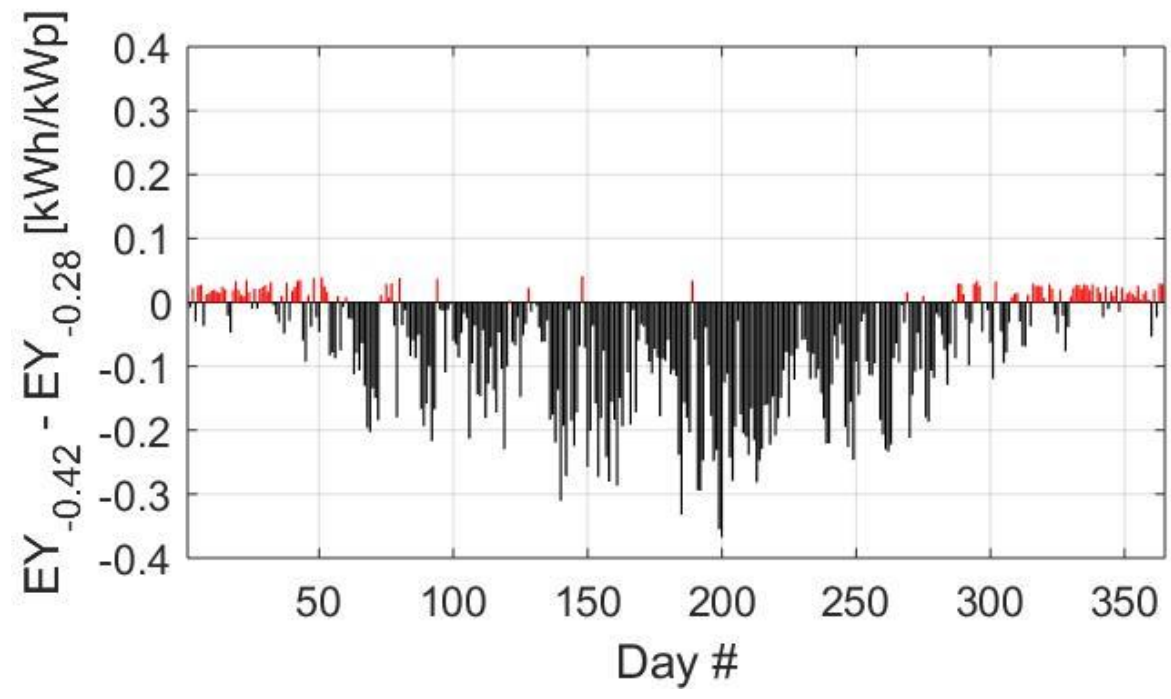

Figure 9: Simulated daily energy yield differences throughout 2014 for Oldenburg. Red bars in the right plot refer to days where the HTC module leads to a higher energy yield (positive values in the graph) than the LTC module. The opposite case is represented by the black negative bars.

230

\subsubsection{Ottawa installation}

At a slightly more southern latitude of $45.4^{\circ} \mathrm{N}$, Ottawa boasts a higher yearly insolation than Oldenburg, but at the same time experiences more extreme temperature variations typical of an inland climate, and a lower mean ambient temperature of $8.8^{\circ} \mathrm{C}$ during operational hours, as is illustrated in Figure 10. This results in a significantly better performance of PV modules with higher thermal coefficients during winter months and comparable performance of HTC and LTC modules during fall months, as shown in Figure 11 and Figure 14.

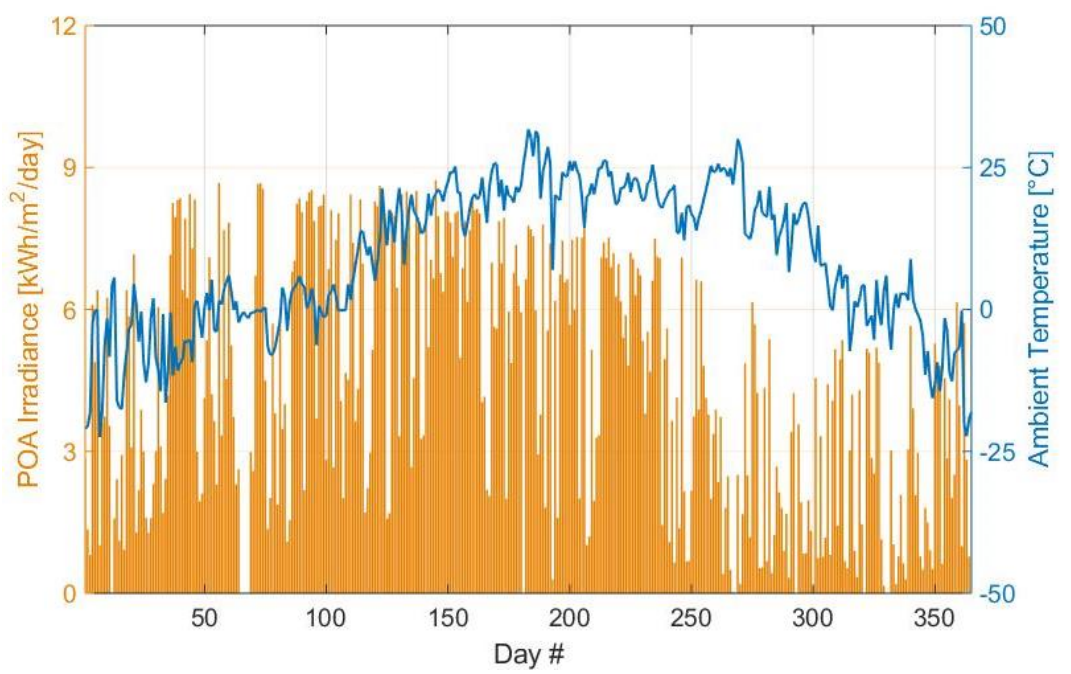

Figure 10: Daily POA insolation (orange bars) and daily average (over operational hours) ambient temperature (blue curve) values throughout 2018, obtained from the Ottawa data used for the simulations. 


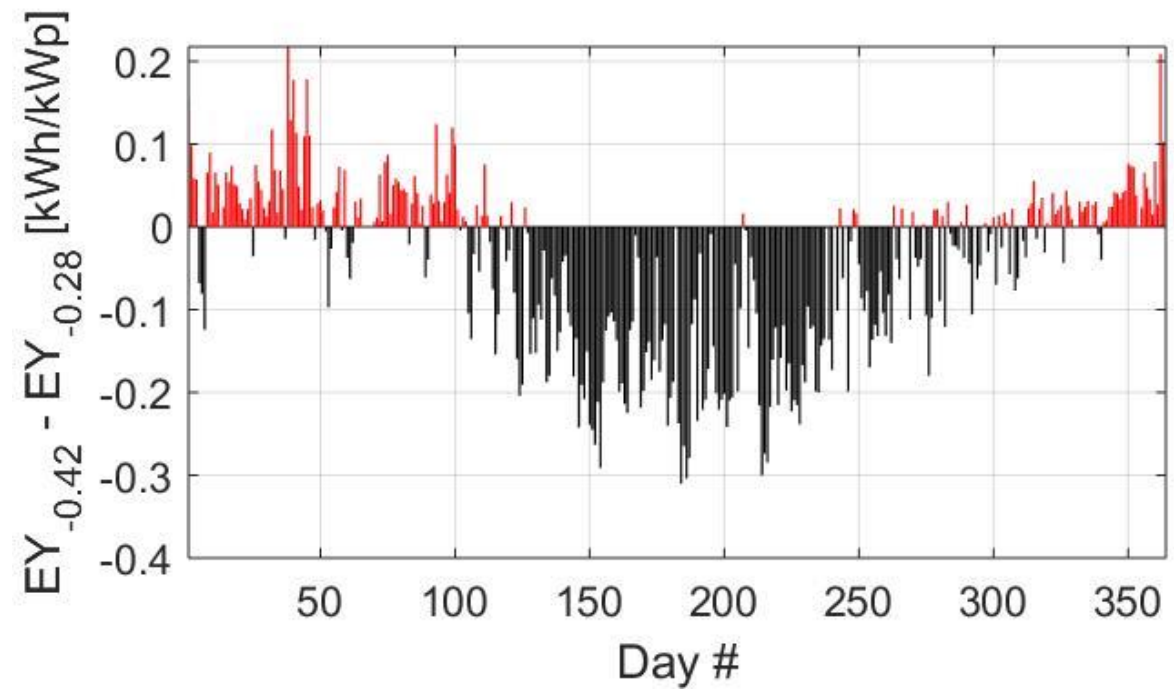

243

244

245

246

247

248

249

250

251

252

253

254

255

256

257

258

259

260

$26 I$

262

263

264

265

266

267

268

269

270

Figure 11: Simulated daily energy yield differences throughout 2018 for Ottawa. Red bars in the right plot refer to days where the HTC module leads to a higher energy yield (positive values in the graph) than the LTC module. The opposite case is represented by the black negative bars.

The use of PV modules with a higher thermal coefficient in this type of climate leads to limited yearly energy yield losses of about $1 \%$. In this location however, heating and electricity consumption are much higher in winter, so the relevance of producing more in winter could favor PV modules with a higher temperature coefficient.

\subsubsection{Tampere installation}

Much more North, at a latitude of $61.5^{\circ} \mathrm{N}$, and as shown in Figure 12, Tampere irradiation is somewhat lower than Oldenburg, especially noticeable in winter. Such low irradiation during winter is partly due to the weather station setup, that is described in detail in [10], where the pyranometer suffers from some shading due to building structures in the morning (all year) and in the evening (in winter), as well as snow/ice coverage in winter.

On the other hand, average ambient temperature over operating hours is deeply below $25^{\circ} \mathrm{C}$, with a yearly average of $6.5^{\circ} \mathrm{C}$. As shown in Figure 13 , in this climate the advantages of a higher temperature coefficient are similar to the Ottawa case, though with more limited gain. As shown in Figure 15, slightly better performance of PV modules with higher thermal coefficients are obtained during winter months whereas slightly worse performance occurs during fall months. As for Ottawa, in Tampere heating and electricity consumption are much higher in colder seasons, so the relevance of producing relatively more during winter could favor PV modules with a higher temperature coefficient. The use of PV modules with a higher temperature coefficient in this type of climate leads to yearly energy yield losses slightly above $1 \%$. 




272

Figure 12: Daily POA insolation (orange bars) and daily average (over operational hours) ambient temperature (blue curve) values throughout 2015, obtained from the

Tampere data used for the simulations.

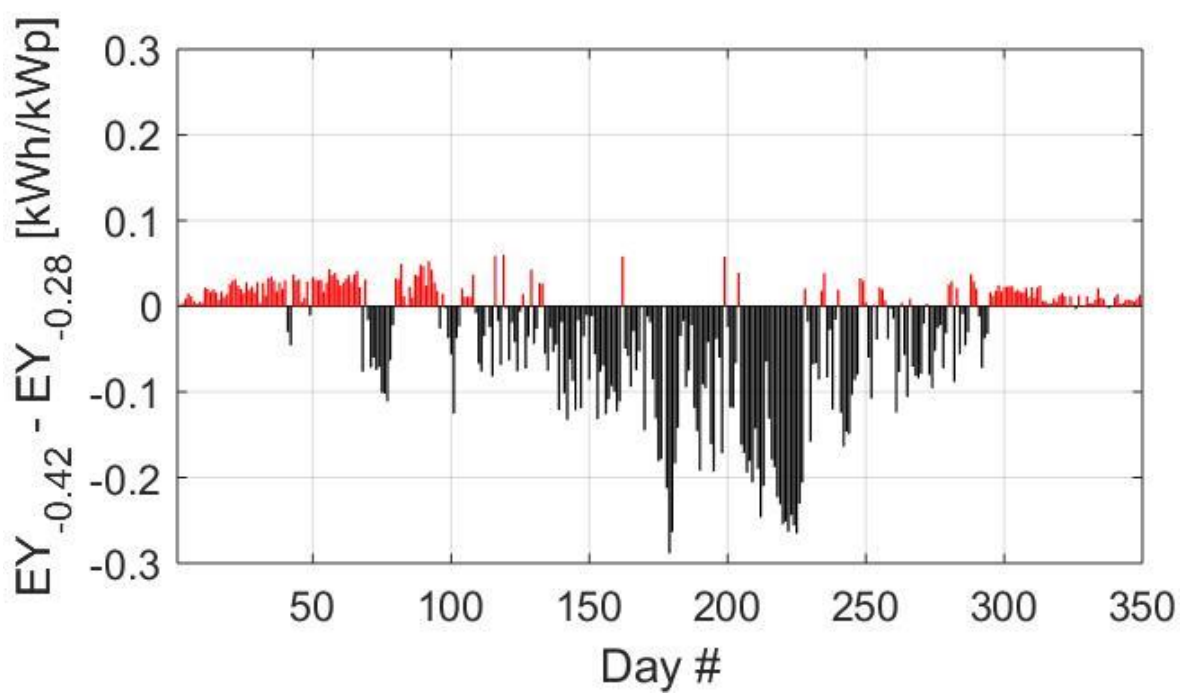

Figure 13: Simulated daily energy yield differences throughout 2015 for Tampere. Red bars in the right plot refer to days where the HTC module leads to a higher energy yield (positive values in the graph) than the LTC module. The opposite case is represented by the black negative bars.

281

\subsubsection{Overview of the simulated installations}

Table 3 recapitulates the results, indicating the impact of temperature coefficient of the PV modules on energy yield, depending on the climate, and based on actual weather data. Though these numbers only give the annual differences, the impact can be much higher at particular moments and locations. 
Table 3: overview of yearly weather data and simulated energy yields for all locations

\begin{tabular}{|l|l|l|l|l|l|}
\hline \multicolumn{2}{|l|}{} & Kuwait & Oldenburg & Ottawa & Tampere \\
\hline Yearly POA irradiance $\left[\mathrm{kWh} / \mathrm{m}^{2}\right]$ & 2381 & 1196 & 1597 & 1121 \\
\hline \multicolumn{2}{|l|}{ Daily variation $\left[\mathrm{kWh} / \mathrm{m}^{2}\right]$} & 1.46 & 2.32 & 2.69 & 2.74 \\
\hline $\begin{array}{l}\text { Mean daytime ambient } \\
\text { temperature* }\left[^{\circ} \mathrm{C}\right]\end{array}$ & 28.9 & 12.3 & 8.8 & 6.5 \\
\hline $\begin{array}{l}\text { Annual energy yield } \\
{[\mathrm{kWh} / \mathrm{kWp}]}\end{array}$ & HTC & 2130 & 1126 & 1560 & 1025 \\
\cline { 2 - 6 } & LTC & 2238 & 1153 & 1577 & 1038 \\
\hline Gain with higher TC [\%] & Annual & -4.8 & -2.4 & -1.1 & -1.2 \\
\hline
\end{tabular}

289

The benefits related to higher thermal coefficients in colder climates are more visible if the energy yield gain is split per season, as in Figure 14. In colder climates as Ottawa and Tampere, energy production during warmer seasons is sacrificed to allow energy yield gain during winter. As a consequence, a better production-demand matching may be obtained. It is worth to note that Tampere's potential is not fully acknowledged due to the used weather data, which was addressed in Subsection 3.1.4.
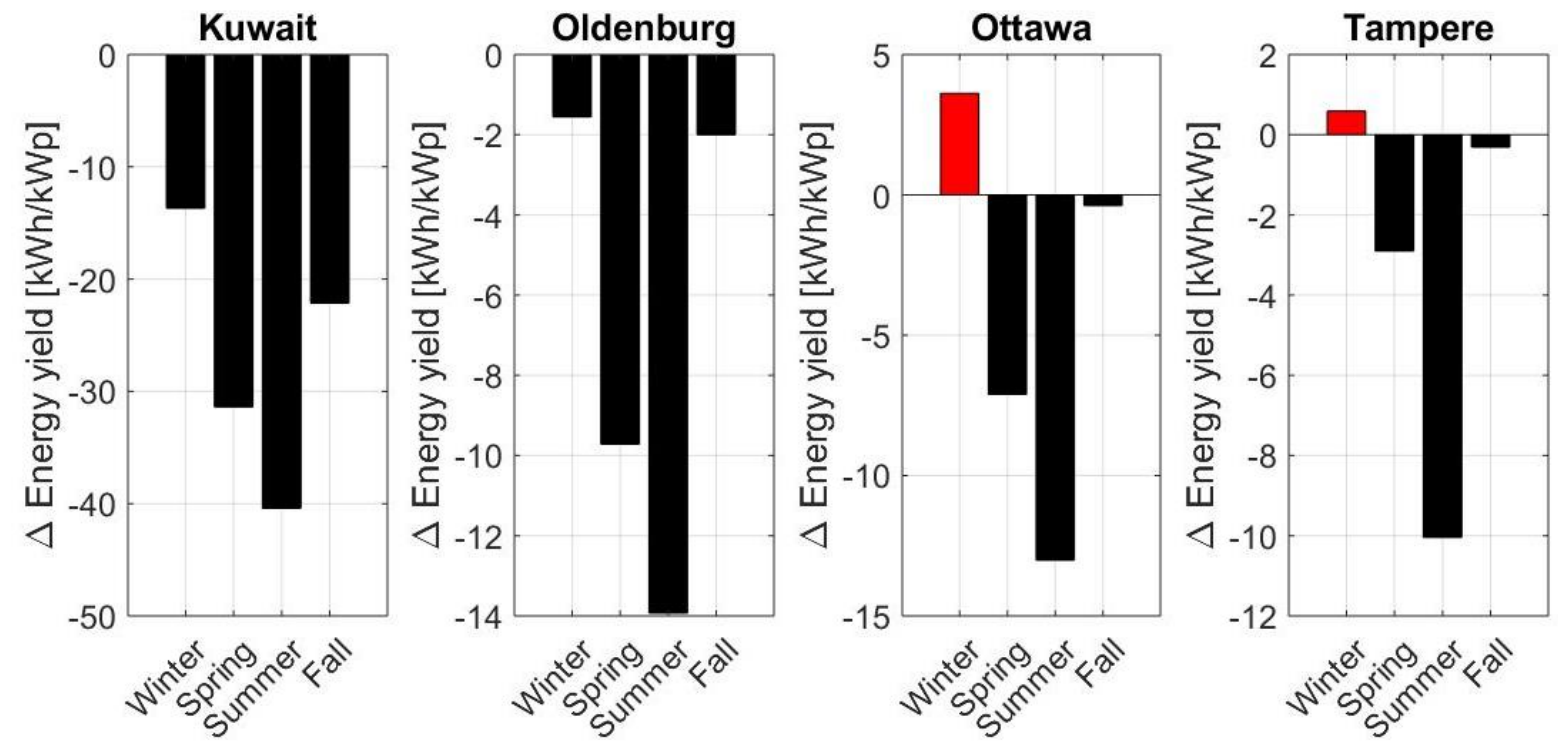

Figure 14: Seasonal absolute gain due to a higher thermal coefficient of the PV module for the different locations. Red bars in the right plot refer to days where the HTC module leads to a higher energy yield (positive values in the graph) than the 
Considering also the absolute energy yield values for the seasons, Figure 15 shows the same graph in terms of relative gains. While losses can be very significant for a Kuwait climate, amounting to almost $7 \%, 1 \%$ additional energy during winter may become interesting for colder climates as Ottawa and Tampere. It is important to note though that the effects of snow accumulation on the PV modules was not considered in the simulations.
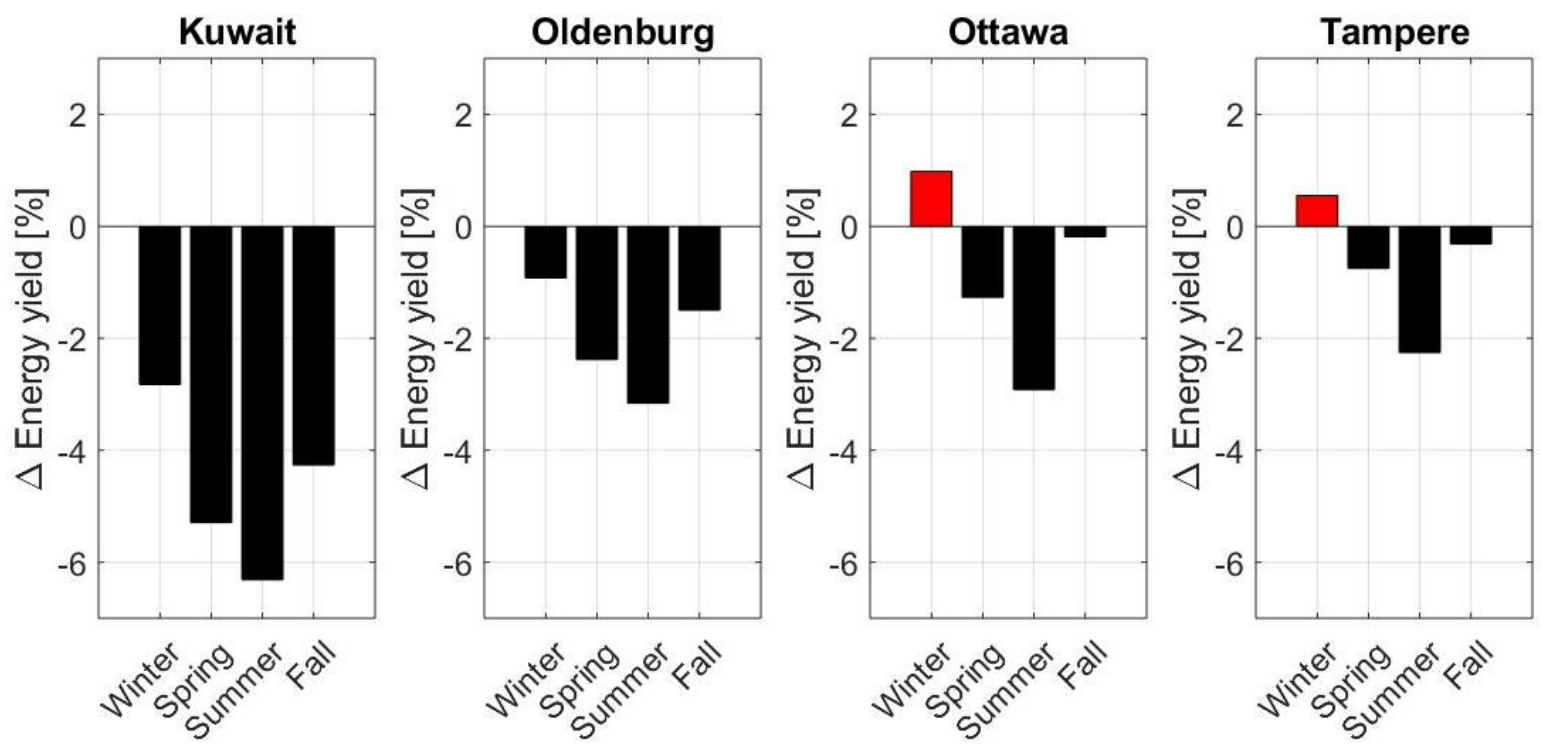

Figure 15: Seasonal relative gain due to higher thermal coefficient for the different locations. Red bars refer to seasons where the HTC module leads to higher energy

\section{$314 \quad 3.2$ Impact of (improved) low light behaviour}

315 In this Section, we will demonstrate that the energy yield of PV modules with higher 316 thermal coefficients in cold climates can be significantly improved if such a higher 317 thermal coefficient is combined with an improved low light performance. To clarify this 318 point, we will start with the analysis of the typical operating conditions of the HTC 319 module under Kuwait and Ottawa climates in terms of irradiation and PV module temperature, summarized in Figure 16 and Table 4. Specifically, Figure 16 shows the occurrences of a given set of operating conditions. Given the minute resolution of the climate datasets, colors in Figure 16 show for how many minutes the PV module was subjected to a certain irradiance (x-axis) and working at a certain module temperature (y-axis). In Table 4, the same results are summarized for given ranges of PV module temperature and irradiation.

326 From Figure 16, it is evident that, as expected, production under Kuwait climate occurs most of the time at medium to high module temperatures, and mainly under two different operating conditions: high irradiation around $1000 \mathrm{~W} / \mathrm{m}^{2}$ with high module temperature in the range $50-60^{\circ} \mathrm{C}$, and low irradiation below $200 \mathrm{~W} / \mathrm{m}^{2}$ with "medium" 
module temperature in the range $22-32^{\circ} \mathrm{C}$. On the other hand, Ottawa climate shows clear peaks at low irradiation around $200 \mathrm{~W} / \mathrm{m}^{2}$ and low module temperature in the range 14-24 ${ }^{\circ} \mathrm{C}$ as well as at $0{ }^{\circ} \mathrm{C}$. Also, energy production below $25^{\circ} \mathrm{C}$ is dominant in such a climate, as shown in Table 4. Purely looking at temperature coefficients, in a climate like Ottawa much better performance of the HTC module is expected than what is shown in the Section 3.1.3. This expectation is skewed because performance at low temperature often happens in low light conditions, such that improvements due to the higher temperature coefficient are counteracted by lower module efficiency at low-light conditions (cf. Figure 5).
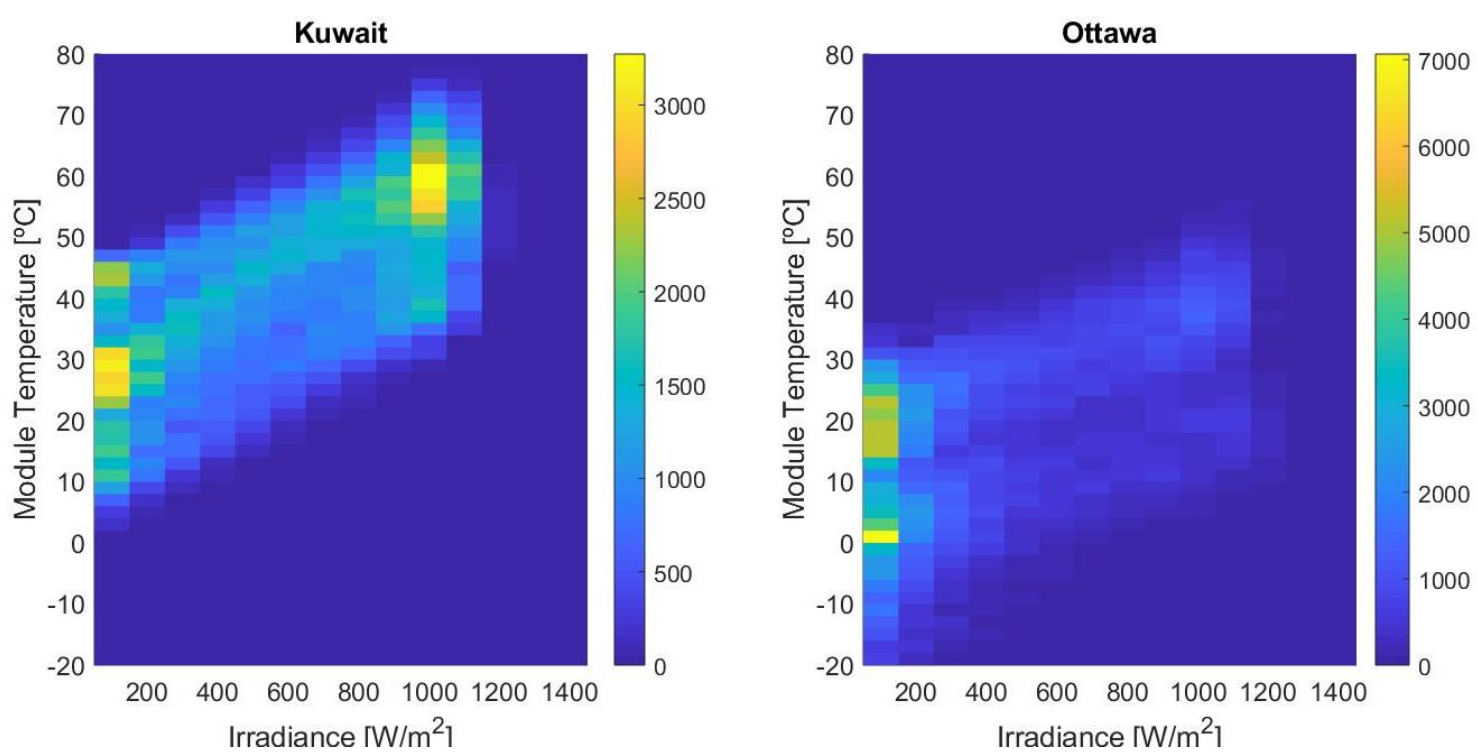

Figure 16: Occurrences (in minutes) of different operating conditions for HTC PV irradiance ( $x$-axis) and working at a certain module temperature ( $y$-axis) during one

Table 4: Occurrences (in percentages of daytime hours in a full year) of different operating conditions, in terms of irradiance and $P V$ module temperature ranges, for a HTC PV module in the Ottawa climate

\begin{tabular}{|c|c|c|c|c|}
\hline Irradiance $\left[\mathrm{W} / \mathrm{m}^{2}\right]$ & $0-200$ & $200-800$ & $800-1500$ & $\begin{array}{c}\text { Total by } \\
\text { row }\end{array}$ \\
\hline Module Temper. ${ }^{\left[{ }^{\circ} \mathrm{C}\right]}$ & & & 6.2 & 70.5 \\
\hline$-45-+25$ & 4.4 & 13.5 & 11.7 & 29.5 \\
\hline$+25-+85$ & 46.0 & 36.2 & 17.8 & \\
\hline Total by column & & 22.7 & 6.2 \\
\hline
\end{tabular}


However, performance at low irradiation can be engineered by proper cell and module design. As shown in [10], shunt and series resistances strongly affect low light performance of PV modules. Of particular interest is the effect of series resistance for tuning the low light behavior: the higher it is, the better the relative efficiency in the mid-irradiation range. With high series resistance, relative efficiencies higher than $100 \%$ can be obtained in the range 300 to $1000 \mathrm{~W} / \mathrm{m}^{2}$. This is the case for the LTC module shown in Figure 5. Therefore, although counter-intuitive, a higher series resistance could be beneficial for modules with higher thermal coefficients in cold climates at high latitude. Again, the starting point has been a real $305 \mathrm{Wp}$ PV module [12] with the same temperature coefficient for maximum power as the HTC module, namely $-0.42 \% /{ }^{\circ} \mathrm{C}$. Parameter fitting has been performed for such a module as discussed before. Since the datasheet does not provide any usable information about the low light performance, the parameter fitting has been done only considering performance at STC and temperature coefficients. Figure 17 shows the results in terms of low-light performance at $25^{\circ} \mathrm{C}$ in comparison with the low temperature coefficient LTC module. It is clear that behavior in low-light is very similar for the two PV modules, although the performance of the LTC module is still better. Compared to Figure 5, low-light performance of this new high temperature coefficient PV module, referred to as $\mathrm{HTC}_{+}$, is much better than the one of $\mathrm{HTC}$. It is worth to note that the fitted series resistance of $\mathrm{HTC}+$ is indeed higher than the fitted series resistance of HTC. This is consistent with the lower Fill Factor, 0.755 and 0.775 , respectively, and the lower number of busbars, 3 and 4, respectively, of HTC+ compared to HTC, as from their datasheets.

372

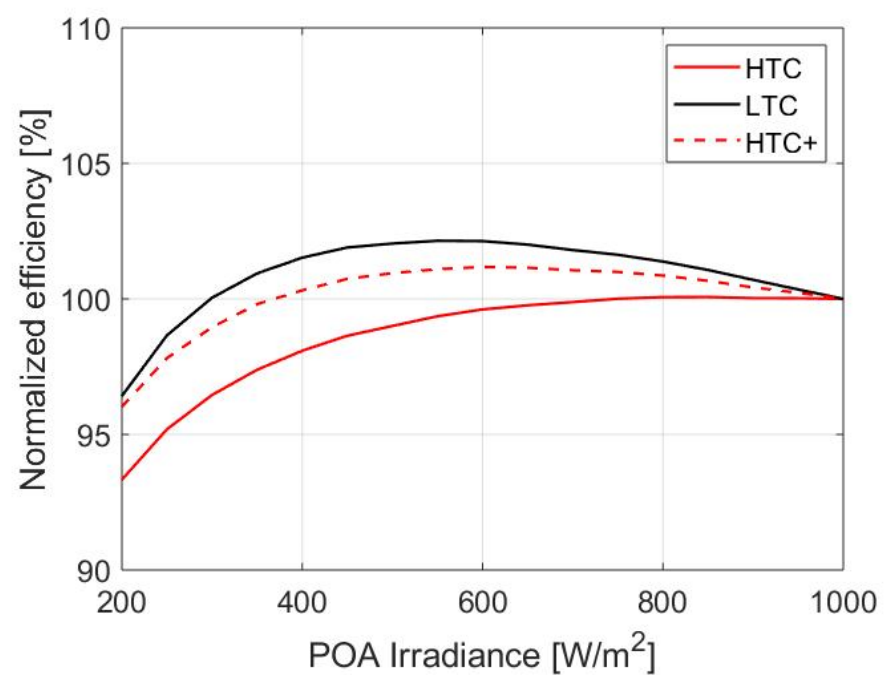

Figure 17: "Relative efficiency of LTC, HTC and HTC+ PV modules as a function of incident irradiance at a fixed cell temperature of $25^{\circ} \mathrm{C}$

The joint effects of higher temperature coefficient and improved low-light performance have been simulated with the new HTC+ PV module model again for the same 4 locations. Results are summarized in Table 5, Figure 18 and Figure 19. Table 5 recapitulates the results, indicating the impact of temperature coefficient of the PV 
modules on energy yield, depending on the climate, based on actual weather data. As for the results presented in Table 3, these numbers only give the annual differences. However, the impact can be much higher at particular moments and locations. The benefits related to higher thermal coefficients in colder climates are more visible if the energy yield gain is split per season, as in Figure 18 and Figure 19. In colder climates, energy production during summer is sacrificed to allow energy yield gain during colder

385

386

387

388

389

390

391

392

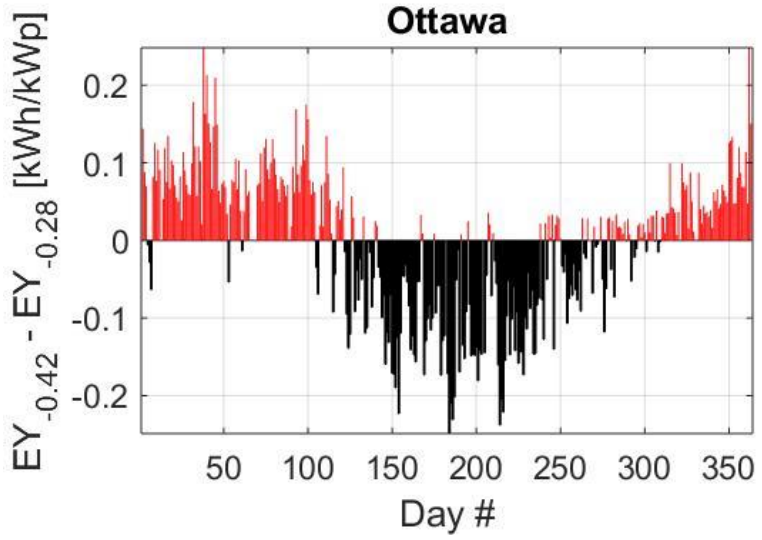

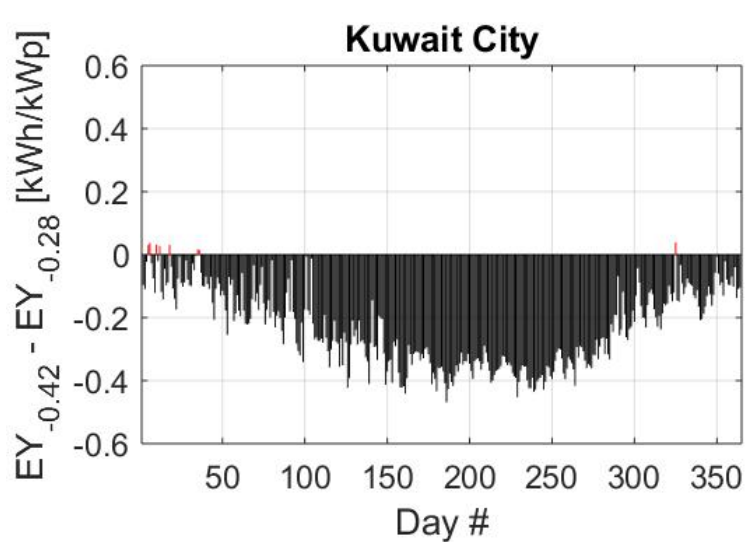

393 for all locations

\begin{tabular}{|l|l|l|l|l|l|}
\hline \multicolumn{2}{|c|}{} & Kuwait & Oldenburg & Ottawa & Tampere \\
\hline $\begin{array}{l}\text { Annual energy yield } \\
{[\mathrm{kWh} / \mathrm{kWp}]}\end{array}$ & $H T C+$ & 2153 & 1142 & 1578 & 1038 \\
\cline { 2 - 7 } & LTC for HTC+ & 2238 & 1153 & 1577 & 1038 \\
\hline $\begin{array}{l}\text { Gain } \\
\text { modules [\%] }\end{array}$ & Annual & -3.8 & -0.9 & -0.1 & +0.0 \\
\hline
\end{tabular}
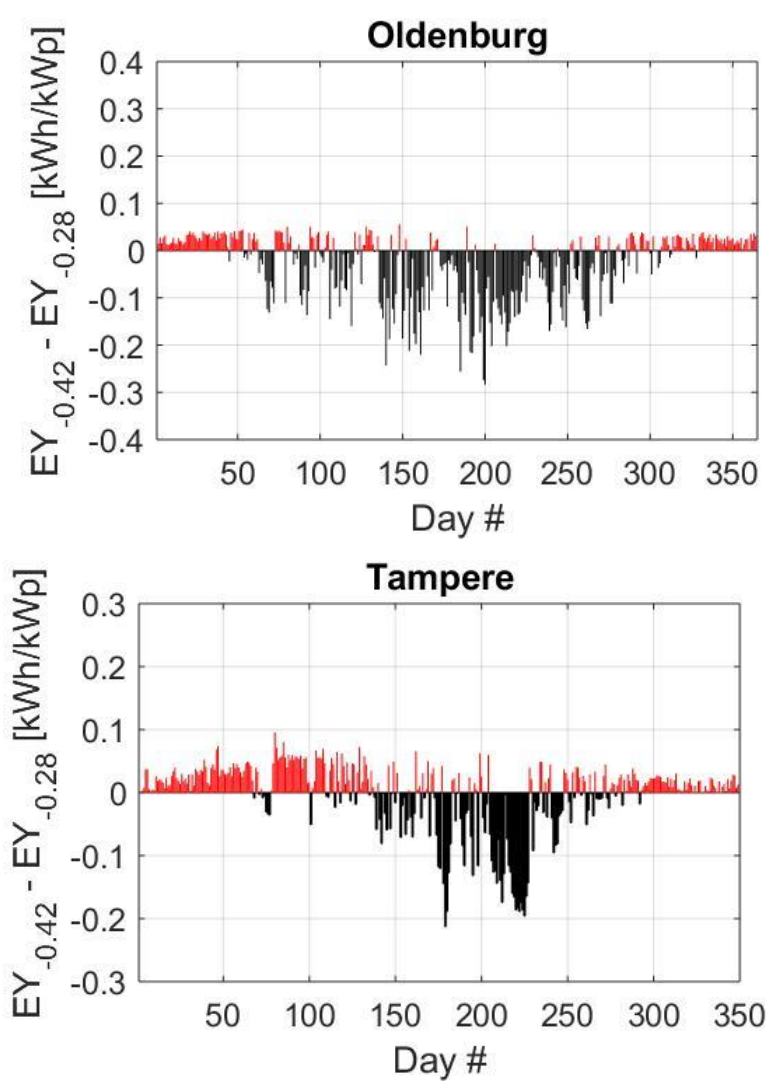

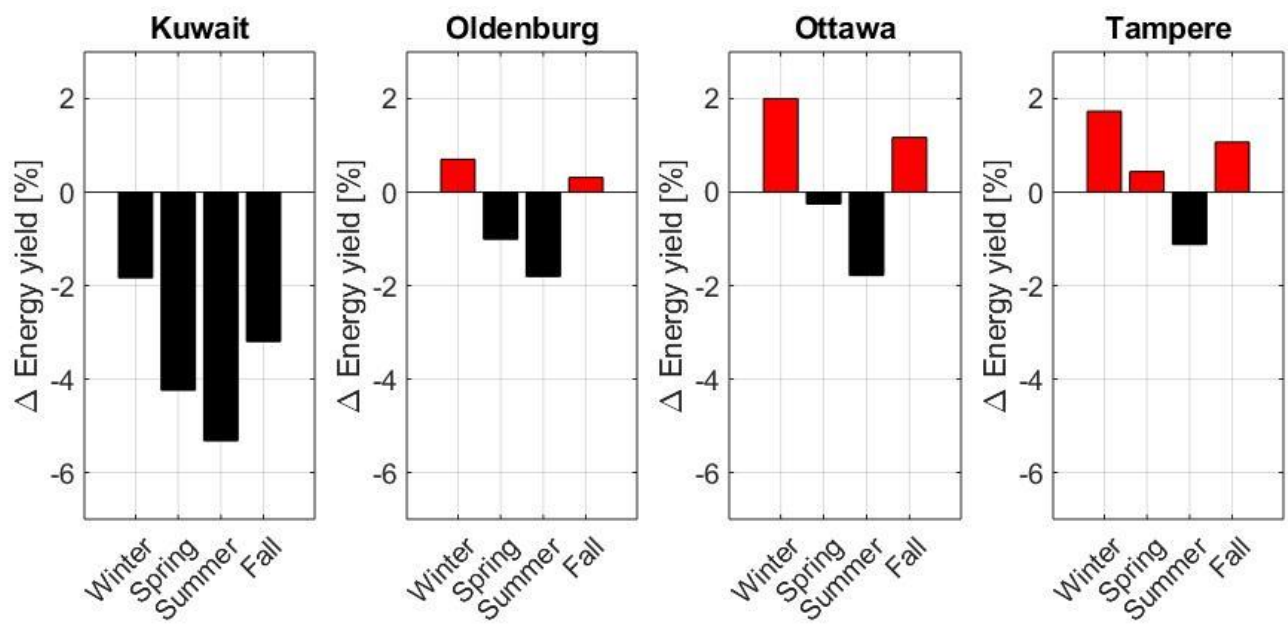

399

400

401

402

403

404

405

406

407

408

409

410

4II

412

413

$4 \mid 4$

415

416

417

418

419

420

421

422

423

424

Figure 19: Seasonal relative energy yield gains of $H T C+P V$ modules with respect to LTC modules for the different locations. Red bars refer to seasons where the HTC+ module leads to a higher energy yield (positive values in the graph) than the LTC module. The opposite case is represented by black negative bars.

Both Oldenburg and Ottawa show energy gains with the HTC+ module during winter and fall. However, in Tampere the advantages of a higher temperature coefficient are visible almost all over the year, with additional energy generated during three seasons out of four. It is only during summer that the PV modules with lower temperature coefficients are performing better, as evident from Figure 18. Additionally, if snow cleaning is duly implemented during winter and shading is avoided, in a climate as Tampere there might even be an overall increase in the yearly energy yield.

\section{Conclusion}

In this paper, we point out the impact of the temperature coefficient of $\mathrm{PV}$ modules on energy yield throughout the year, indicating also the somewhat counterintuitive benefits that a high temperature coefficient may have depending on the climate where it is operational. If low-light behavior is not optimized and only a higher temperature coefficient is considered, some seasonal gain is obtained in 2 out of 4 locations, namely Tampere and Ottawa, whereas in Oldenburg's and Kuwait's climate PV modules with a lower temperature coefficient would lead to better performance. However, when a higher temperature coefficient is accompanied by improved low-light performance, the benefits of such PV modules become clear. Except for the Kuwait case, higher production during cold seasons, beneficial for a better productiondemand matching, is obtained in all the other cases. For the specific case of Tampere, the use of such PV modules could even lead to an overall increase of the yearly energy 
yield. Considering little attention is currently paid to times of low PV production, we also point out the potential impact of shading objects or snow cover that may affect results.

\section{Context and outlook}

The findings here are meant to fit into a bigger picture in the future where PV production will be optimized to times of electricity scarcity rather than maximizing annual energy yield. Such optimization should then also include "suboptimal" tilt angles combined with the effects reported here. Furthermore, the potential gains and losses here are only expressed as a function of produced electrical energy, as most scientific and technical approach, but market-driven dynamic pricing will further alter the outcome and will obviously need to be assessed in any future practical implementation.

\section{Acknowledgment}

This project has received funding from the European Union's Horizon 2020 research and innovation programme under the Marie Skłodowska-Curie grant agreement No. 751159. The work in this paper was partially funded by the Kuwait Foundation for the Advancement of Sciences under project number CN18-15EE-01.

\section{References}

[1] Kuwait Government, Ministry Of Electricity \& Water Statistical Year Book 2016 (Electrical Energy).

[2] H. Goverde et al., "Energy Yield Prediction Model for PV Modules Including Spatial and Temporal Effects", 29th European Photovoltaic Solar Energy Conference and Exhibition (EU PVSEC), pp. 3292 - 3296, 2014.

[3] I. T. Horváth, H. Goverde, P. Manganiello, J. Govaerts, L. Tous, B. Aldalali, E. Vörösházi, J. Szlufcik, F. Catthoor, J. Poortmans, Photovoltaic energy yield modelling under desert and moderate climates: What-if exploration of different cell technologies, Solar Energy, Volume 173, 2018, Pages 728-739, ISSN 0038-092X, https://doi.org/10.1016/i.solener.2018.07.079.

[4] R. Perez et al., "Modeling daylight availability and irradiance components from direct and global irradiance". Solar Energy 44 (5), pp. 271-289, 1990.

[5] R. Perez et al., "The Development and Verification of the Perez Diffuse Radiation Model". SAND88-7030. 1988.

[6] Jacobson M. Z., Jadhav V., "World estimates of PV optimal tilt angles and ratios of sunlight incident upon tilted and tracked PV panels relative to horizontal panels", Solar Energy, 169 (2018), 55-66. 
[7] Beck, H.E., Zimmermann, N. E., McVicar, T. R., Vergopolan, N., Berg, A., \& Wood, E. F. - "Present and future Köppen-Geiger climate classification maps at 1-km resolution". Nature Scientific Data. DOI:10.1038/sdata.2018.214.

[8] ET Solar ET-M660305WW/WB PV module. Datasheet available online (last check November 29th, 2019$)$ : https://amazingsolar.com.au/wp-content/uploads/2019/02/ETMono-60-cell-290-305W.pdf

[9] NSP D6H_E3A PV module. Datasheet available online (last check November $\left.29^{\text {th }}, 2019\right)$ : https://webbuilder3.asiannet.com/ftp/2257/NSP 1608 Hello325 D6H E3A WS 01.pdf [10] D. Torres Lobera, A. Mäki, J. Huusari, K. Lappalainen, T. Suntio, S. Valkealahti, Operation of TUT solar PV power station research plant under partial shading caused by snow and buildings, International Journal of Photoenergy. 2013 (2013). https://doi.org/10.1155/2013/837310.

[11] Litzenburger, B., et al., "Low Light Performance of Solar Cells and Modules", 29"th European Photovoltaic Solar Energy Conference, Amsterdam, Netherlands, $22^{\text {nd }}-26^{\text {th }}$ September 2014.

[12] Up Solar Mono Series 60 cells PV Module. Datasheet available online (last check November

29th, 2019):

http://www.eco481 distributing.com/assets/images/Upsolar\%20mono\%20285-305W\%20spec\%20sheet.pdf 